\title{
University-industry collaborations in Pakistan: current challenges and future opportunities
}

DOI:

10.1108/FS-12-2020-0133

\section{Document Version}

Accepted author manuscript

Link to publication record in Manchester Research Explorer

\section{Citation for published version (APA):}

Malik, K., Bashir, T., \& Ali, T. (2021). University-industry collaborations in Pakistan: current challenges and future opportunities. Foresight. https://doi.org/10.1108/FS-12-2020-0133

\section{Published in:}

Foresight

\section{Citing this paper}

Please note that where the full-text provided on Manchester Research Explorer is the Author Accepted Manuscript or Proof version this may differ from the final Published version. If citing, it is advised that you check and use the publisher's definitive version.

\section{General rights}

Copyright and moral rights for the publications made accessible in the Research Explorer are retained by the authors and/or other copyright owners and it is a condition of accessing publications that users recognise and abide by the legal requirements associated with these rights.

\section{Takedown policy}

If you believe that this document breaches copyright please refer to the University of Manchester's Takedown Procedures [http://man.ac.uk/04Y6Bo] or contact uml.scholarlycommunications@manchester.ac.uk providing relevant details, so we can investigate your claim.

\section{OPEN ACCESS}




\section{University-industry collaborations in Pakistan: current challenges and future opportunities.}

\begin{tabular}{|r|l|}
\hline Journal: & Foresight \\
\hline Manuscript ID & fs-12-2020-0133.R1 \\
\hline Manuscript Type: & Original Article \\
\hline Keywords: & University-industry, Knowledge transfer, Innovation, Trust, Pakistan \\
\hline
\end{tabular}


MANUSCRIPT DETAILS: University-industry collaborations in Pakistan: current challenges and future opportunities.

: paper aims to identify current challenges that hinder university-industry (U-I) collaboration in Pakistan and presents future opportunities for promoting such collaborations in developing countries.exploratory study presents new empirical evidence obtained from Pakistan via a questionnaire survey of twenty-four universities, twenty-five interviews with key stakeholders including industry managers and outputs from a high level workshop event.there is limited evidence of university-industry engagement in Pakistan, our findings show that a lack of coordination between government, universities and industrial firms has hindered knowledge transfer between universities and industry. Such steps as utilising intermediaries to help broker effective collaborations and building trust based relationships can help in socialising these types of scientific activities.overall conclusions drawn from this exploratory study can only be tentative, since the findings represent a snapshot of current U-I collaboration initiatives in Pakistan.stringent policy interventions from government entities, as well as more universities willing to invite industry input on their board of studies might enable co-development of some university curriculums with industry partners. U-I collaborations could also help to boost innovation efforts in developing country firms.paper also offers awareness into benefits of teaching activity collaboration with industry partners, which has been an under explored area of past U-I collaboration studies. The findings should be of interest for both innovation policy and higher education policy researchers. 


\title{
University-industry collaborations in Pakistan: current challenges and future opportunities.
}

\begin{abstract}
Purpose - This paper aims to identify current challenges that hinder university-industry (U-I) collaboration in Pakistan and presents future opportunities for promoting such collaborations in developing countries.

Design/methodology/approach - This exploratory study presents new empirical evidence obtained from Pakistan via a questionnaire survey of twenty-four universities, twenty-five interviews with key stakeholders including industry managers and outputs from a high level workshop event.
\end{abstract}

Findings - Although there is limited evidence of university-industry engagement in Pakistan, our findings show that a lack of coordination between government, universities and industrial firms has hindered knowledge transfer between universities and industry. Such steps as utilising intermediaries to help broker effective collaborations and building trust based relationships can help in socialising these types of scientific activities.

Research limitations/implications - Any overall conclusions drawn from this exploratory study can only be tentative, since the findings represent a snapshot of current $U-I$ collaboration initiatives in Pakistan.

Practical implications - Less stringent policy interventions from government entities, as well as more universities willing to invite industry input on their board of studies might enable codevelopment of some university curriculums with industry partners. U-I collaborations could also help to boost innovation efforts in developing country firms.

Originality/value - This paper also offers awareness into benefits of teaching activity collaboration with industry partners, which has been an under explored area of past U-I 
collaboration studies. The findings should be of interest for both innovation policy and higher education policy researchers.

Keywords University-industry, Knowledge transfer, Innovation, Trust, Pakistan.

Paper type Research paper

\section{Introduction}

It is generally acknowledged that as knowledge producers, universities contribute to increasing regional competitiveness through a range of activities, including research, teaching and technology transfer. However, little is known about the recent nature of university-industry (U-I) collaboration taking place in developing countries. One of the few recent studies, by Schiller \& Lee (2015), presents some comparative analysis of U-I collaborations from a number of Asian emerging and developing economies. This study highlighted the importance of building trust-based relationships to help implement U-I collaborations, which might be due to a lack of historical experience with such collaborations. Hence, this paper presents new research findings from Pakistan to show how some universities are initiating collaborations with industrial firms. We also present some key challenges faced and the types of opportunities presented in pursuing such collaborations, both from university and industry perspectives.

University and industry engagement has progressed slowly in Pakistan as is the case with most developing countries. Many advanced economies had faced such a situation in the past where it had taken considerable time for firms to recognise that industrial R\&D may greatly benefit from collaboration with universities as a means to acquire new scientific competencies and fresh insights. In Pakistan, the Higher Education Commission (HEC) launched a University-Industry Interaction project in 2005, which was an early recognition that U-I collaboration might help universities to commercialise some of their research outputs 
with industry partners. However, there appears to be no policy level evaluation of this initiative in terms of any positive outcomes (Afzal et al., 2014). Furthermore, many of Pakistan's private industry sectors operate with few university graduates and possess poor research and development (R\&D) facilities. Hence, this has resulted in very few academic linkages of note (Zaman, 2011). One notable area of progress is Pakistan's long term development agenda Pakistan 2025. This agenda acknowledged the critical importance of university-industry linkages for building a knowledge-based economy, especially through government, private sector and academia/research partnerships (Planning Commission, 2014).

The findings presented in this paper should be of interest for innovation policy and higher education policy researchers and practitioners. We seek to show how future development of U-I collaborations in Pakistan should be viewed as a holistic process of change involving key institutions such as government agencies, policymakers, universities (including faculty and students), industrial firms and any intermediary organisations. Hence, our paper addresses the following key research questions:

- Is there any evidence of U-I collaboration pursued by leading Pakistani universities in recent years?

- What are the main benefits and obstacles to U-I collaboration in Pakistan?

- What are the main policy implications for U-I collaboration in Pakistan based on the perspectives of universities, industry and other key stakeholders?

The remainder of this paper is organised as follows. Section 2 presents a literature review to help position the paper. Section 3 provides a brief of the Pakistan science and innovation policy context. Section 4 presents our research methodology. Section 5 presents the findings derived from our survey, interviews and a national workshop event. Section 6 
presents some analysis by examining key lessons for theory and practice. Section 7 provides some concluding remarks.

\section{Literature Review}

The UNESCO Science report (2015) suggested that the promotion of more public-private partnerships can help to create synergies between universities and industrial companies in South Asia. Hence laying the foundations to encourage industry-led innovations. Funding for U-I collaborative initiatives and fiscal policies is much needed where there is a necessity to upgrade technical capabilities in certain sectors, such as the telecommunications industry in Kazakhstan (Smirnova, 2016). As well as encouraging knowledge transfer between universities and industrial firms, U-I collaborations may help increase academic performance of university faculty staff. For example, enabling some research outputs from universities to compensate for the low investment of private $R \& D$ often found in most developing countries (Garcia et al., 2020).

Government policy specifically targeted at promoting U-I collaboration in R\&D projects can sometimes have a positive impact on those firms looking to increase the level of private investment in $\mathrm{R} \& \mathrm{D}$, which can lead to the creation of new knowledge in the economy and increasing job opportunities in the labour market (Scandura, 2016). Another government policy measure that can have a positive effect on collaboration involving university and industry actors is policies that help with the creation of science and technology parks where such actors are in close geographical proximity, as confirmed in Spain and other countries who have introduced this type of policy in recent times (Vásquez-Urriago et al., 2016). Some government policy measures promoting staff mobility between universities and industry may help to initiate deeper collaborations. For example, the Thailand government has introduced a talent mobility programme that encourages university researchers to spend some time working in industry as full-time or part-time staff. This type of working time with industry 
may act as a catalyst to develop deeper relationships between the university and the industrial firm (Pittayasophon \& Intarakumnerd, 2017).

In many industry sectors, SMEs might benefit from government policies that promote the role of intermediary organisations, such as public or private organisations acting as agents transferring technology between hosts (typically universities) and users in industry (Shohert \& Prevezer, 1996). Howells (2006) refers to such organisations as 'innovation intermediaries', since they can play a prominent brokering and mediating role in helping to encourage more effective U-I collaborations. However, there are barriers associated with U-I collaboration, such as divergent objectives and organisational cultures, which must be taken into account when brokering these types of relationships (Mascarenhas et al., 2018). It may also be beneficial for innovation intermediaries to identify university research groups or university technology transfer offices to help universities connect with industrial firms. For example, assisting university researchers to develop their inventions into mature concepts that would attract the attention of industrial firms (Galvao et al., 2020; Patana et al., 2013).

In the context of U-I collaborations in developing countries, it is important to stress that U-I collaborations such as co-development of curriculum that are targeted towards improving teaching capabilities should be further explored, as the impact of such initiatives is likely to be far more significant on human capital development than research and entrepreneurial-based collaborations (Laredo, 2007; Borah et al., 2019). Hence some thirdmission activities of universities can be synergistic with the two other missions (teaching and research) of many universities, by helping student recruitment, and partnering with firms for collaborative projects (Piirainen et al., 2016). Some recent studies have examined the dynamics of educational focused U-I collaborations which may have mutual benefits for universities and industrial firms (Cavallone et al., 2019; Sin \& Amaral, 2017). Hence these studies highlight some useful incentives for universities and industry when they engage in 
educational focused type U-I collaborations, and describe how and in what forms these collaborations are organised. Knowing these and other factors linked to educational focused U-I collaborations is important for guiding universities, industrial firms and government policymakers on building a supportive institutional environment for such U-I collaborations.

One key challenge often faced by university researchers in executing collaborations with industry, is that they may not possess previous experience of such collaborations and are comfortable with intense company interactions. Therefore, such activities seem highly dependent on the profiles of the key personnel within the university research units (Knudsen et al., 2019). In some developing countries, there is also evidence of university faculty staff opting for personal private contracts with companies to offer some consulting services to firms, as this can help supplement low university salaries. However, this could reduce the benefits accruing to the university, as well as create conflicts of time allocation on the part of the university faculty members (Wickramasinghe \& Malik, 2018). This can be seen as an informal ad hoc aspect of U-I interactions, but also highlights a wider gap in the literature regarding what is known about collaboration between universities and the business community of less developed regions of the world, as confirmed by a systematic review of the U-I collaboration literature by Mascarenhas et al. (2018). This review reveals that it is unclear what mechanisms of collaboration might work well in in developing countries.

\section{The Pakistan context}

Science and technology policy play a significant role in enhancing the STI system of a country. Pakistan's first national Science, Technology and Innovation Policy was formulated in 2012 (Government of Pakistan, 2012). It was the first time that the government had formally recognised innovation as being a long-term strategy for driving economic growth. The HEC supports the establishment of Business Incubation Centres (BICs) in Pakistan's public sector universities to provide basic infrastructure and allied facilities for researchers 
and young entrepreneurs who are interested in developing early-stage business ventures. As of 2017, 20 BICs have been established at different universities in Pakistan (Higher Education Commission, 2017).

In Pakistan, the importance of university-industry relationships has not been fully recognised, especially by the private sector. Thus, the concept of U-I collaboration has negligible practice in Pakistan. Another reason for this lack of collaboration is that Pakistani firms generally develop very few new products, whereas many universities do not share a culture of pursuing research activities (Bashir et al. 2010; Ali \& Tahir, 2017). There have also been some calls for the creation of business and technology centres as well as industrial clusters in each of Pakistan's provinces, which can help to co-locate some universities closer to industry and help facilitate collaborations (Universities UK International, 2017). In terms of policy implications, Bhutto \& Lohana (2018) suggest that higher education policy should modify the composition of the Board of Studies in universities by including at least one board member who has an industry background.

\section{Methodology}

This study utilises empirical data that was collected from Pakistan in 2017-18 and has been subsequently analysed for this paper. We obtained data from a questionnaire survey of Pakistani universities, where key senior level academic staff were targeted, as they needed to possess some knowledge about U-I collaborations. We received completed questionnaires from thirty-four Academics working across twenty-four Pakistani universities from all parts of the country. The twenty-four universities were identified with the assistance of national level experts from two Government departments, the HEC, the PCST, and some ORICs (Offices of Research and Innovation Commercialization, which are small offices based inside some universities helping to promote technology transfer and commercialisation from 
universities to industry). The universities contacted had to have experience with some form of U-I collaboration in recent years. We analysed the survey findings using basic statistical techniques.

We also collected empirical data from conducting a total of twenty-five semistructured interviews with a range of university and industry representatives. This includes thirteen Senior Academics and Heads of Departments from seven universities (out of twentyfour surveyed via our questionnaire) and eight business managers from technology-based firms that have some previous experience of collaborating with universities. The interviews included four senior officials working in ORIC offices who possessed experience of promoting some forms of U-I collaboration. To preserve their anonymity, we cannot attribute findings presented in this paper to specific universities and firms. The duration of the interviews was typically seventy to 100 minutes, with two researchers conducting face-toface interviews with all the persons who had agreed to participate in our study. To analyse the interview findings, the interview transcripts were manually coded one interview at a time, helping to come up with the coding lists linked to our research questions. We organised the coded data into a practicable number of first order themes by amalgamating various codes based on resemblances and relations amongst (Strauss and Corbin, 1998).

To the best of our knowledge there is no recent (last decade) national level survey of U-I collaboration in Pakistan. Hence, an important part of our research study was the awareness raising exercise, which led to the preparation of a high-level workshop (held in Islamabad, 2017) that contained some focus group activities. The workshop was attended by more than 150 eminent scientists, industrialists and academics, which included the Federal Minister for Science \& Technology (Government of Pakistan), the Executive Director of the Higher Education Commission of Pakistan, and the Chairman of the Pakistan Council for Science \& Technology all providing valuable insights. 


\section{Findings}

\subsection{Questionnaire survey}

Our questionnaire survey findings show that some Pakistani universities have attempted to implement different modes of collaborative links with local industry, where some links have worked reasonably well, but others have not worked as well. As presented in Figure 1, no. 1 'joint research project/ publication' is the most widely pursued mode of U-I collaboration, which was selected by $81 \%$ of the survey respondents. This was followed by: no. 2 'student placements in industry' (selected by $73 \%$ of respondents); no. 3 'joint conference/ seminar event' (selected by $65 \%$ of respondents); no. 4 'consultancy to industry by academic staff' (selected by $62 \%$ of respondents); no. 5 'research contracted to university staff' (selected by $42 \%$ of respondents); no. 6 'industry input into curriculum design' (selected by $38 \%$ of respondents); no. 7 'training industry staff at university' (selected by $38 \%$ of respondents). Two other modes of collaboration pursued by the universities (not highlighted on Figure 1) are 'licensing technologies to industrial firms' (selected by $19 \%$ of respondents) and ‘industry staff on visiting placement in university’ (selected by 19\% of respondents).

\section{*INSERT FIGURE 1 HERE}

Table I shows a range of U-I collaboration mechanisms that the Pakistani universities responding to our survey believe would be helpful in establishing such links. These include some highly ranked mechanisms. For example, an invention that originates in the university leading to new knowledge or leading to the formation of a new company, as well as others such as participating in joint research with industry, and gaining access to some testing facilities in industry. 


\section{*INSERT TABLE I HERE}

The barriers to establishing collaborative links with industry are shown in Table II. To calculate the means shown, a score of 'Three' was given to a 'very significant' barrier, 'Two' was given for a 'moderately significant' barrier and 'One' was given for a 'not significant' barrier. As illustrated in Figure 2, the two highest ranked barriers hindering the establishment of U-I links are: industry does not consider universities to be reliable partners; and no/few rewards for academics to work with industry.

\section{*INSERT TABLE II HERE}

*INSERT FIGURE 2 HERE

Our survey also provided some basic insights into the role of Faculty staff and students when universities initiate collaborative linkages with industrial firms. As shown in Table III, 53 per cent of the surveyed universities have a formal policy that allows Faculty staff to engage with external activities, including consultancy work for industry. Interestingly, 85 per cent of the university respondents also confirmed that Faculty staff should be evaluated on their external work and contributions to industry. A very high proportion of the survey respondents (91 per cent) confirmed that their university encourages students to conduct research projects inside firms or via any other form of collaboration with industry. 


\section{*INSERT TABLE III HERE}

\subsection{Interviews}

Some of our study interviews were conducted with senior staff from universities. The staff needed to have had some form of prior experience with any modes of U-I collaboration. Two prominent types of U-I collaboration commented upon by university academics are: 'joint research projects with industry' and 'student placements in industry'. For example, some universities have already undertaken research that has the potential for promising future innovations, but now require collaboration with industry to help with pilot plant testing and commercialisation feasibility. Here, one university academic confirmed that his research unit had developed new solar panel technologies, but the true potential of these technologies can only be realised if industry is willing to help with prototype testing and market feasibility work. In the area of earth sciences, one university has undertaken some early research that requires collaborators from the mining industry to assist with feasibility studies to realise the true potential of this early research work. In the area of agricultural sciences, one university academic mentioned that there appears to be great potential in the hot water treatment of mangoes, a major fruit export of Pakistan. However, this potential can only be realised if there could be some form of U-I collaboration investigating the possibility of scaling up this type of testing, as it is only currently being done in one factory in the whole of the country.

A few academics mentioned that many long-established universities could learn some lessons from young entrepreneurial universities (e.g. NUST) which have identified key departments such as Mechanical Engineering who are adept at working with industry where firms often require a quick solution to a problem. With this type of arrangement 
there is also evidence that some SME firms are approaching ORICs (small innovation commercialisation units inside some universities) to seek assistance from universities to help address innovation project challenges, especially via the university science and engineering departments. ORICs also play a proactive role in promoting faculty projects outside of the university, with the aim of connecting faculty staff to SMEs and large firms.

One major theme arising from interviews with academics and the ORIC officers concerns the building of a trust-based relationship between universities and industry. The majority of interviewees stressed the need to develop trust, as this is seen as invaluable in developing confidence in the ability of the collaborating partners to deliver what is being promised as part of a collaborative initiative. The building of a trust-based relationship could also help to address the issue whereby some universities believe industry is only interested in monetary matters, mainly relating to short-term profits, and has little or no interest in engaging with university research that is perceived as long-term with no immediate benefits for improving firm profitability and competitiveness.

As also confirmed by our questionnaire survey responses, almost all interviewees stated that there needs to be some consideration given to incentivising academics to work closely with industry, which has implications for university staff evaluation procedures and higher education policy in Pakistan. The interviewees confirmed that there are no rewards for academics who collaborate with industry in the current university evaluation criteria. This is well captured by one university professor, who stated that: 'Academic promotions will only ever be based on research publications, not on industry-based projects'. One university head of a major department also elaborated on this point by stating:

'I have little hope in improving U-I collaboration as my university's current academic promotions criteria needs to be changed in order to create more industry relationships. At present publications are the top criteria for academic promotions, so 


\begin{abstract}
how can I encourage my staff to reach out to industry if there is little recognition of this type of engagement within our evaluation criteria?'
\end{abstract}

As is the case with many other developing countries, lack of finance in a resource constrained environment continues to be a major hurdle when analysing U-I collaborations in Pakistan. However, some interviewees suggested several ways to help build a collaborative culture between universities and industry, even with limited financial resources. For example, interviewees mentioned that their organisations would benefit by attending and contributing to some key sector forums where certain industry sectors have been identified as key strategic sectors for the economy (e.g. IT, telecommunications, environmental science and others). This could help to encourage universities to initiate some knowledge transfer seminars at such forums where new lines of research and technological discoveries can be presented to a wider audience of other academics and industry professionals. Likewise, these types of forums may be beneficial for industrial firms as industry representatives could recommend potential commercial applications for university generated research outputs.

Our interviews with some technology-based firms revealed useful industry perspectives, which appear to be closely aligned with the challenges of U-I collaboration as highlighted by the universities. The industry representatives unanimously identified some common barriers to U-I collaboration, which include high levels of bureaucracy that is often found inside universities, a mismatch between the objectives of industry and university, some universities do not maintain links with industry as they are preoccupied with their teaching, and scarcity of government funding support means such initiatives are not widespread in Pakistan. 
More specifically, one industry manager stated that firms often require something that is tangible and can be ideally seen from the start. A pharmaceuticals industry manager stated that it would be helpful to see more initiatives that help industry staff to connect with universities via seminars, as this is helpful in building contacts and relationships, especially for SMEs who might otherwise be unaware of some key developments in universities that could have future potential for firms. One managing director of a low technology-based manufacturing firm reflected on the difficulties encountered when previously attempting to initiate some collaboration with two universities, stating:

'Although we have a scarcity of resources to collaborate with universities, my company have attempted to connect with a local university, but it was not a good experience. We did not fully understand what the university can offer to us, partly because of a lack of tradition to collaborate externally. But one major barrier that concerns me is the inefficient bureaucracy that we have to face when dealing with simple issues in setting-up a contract with the university'.

\subsection{Workshop and focus groups}

We organised a workshop event in Islamabad in 2017 on the theme of university-industry collaborative interactions, with the intention to draw out some policy and practical implications for Pakistan. This was one of the rare national forums that brought together Government officials, policy advisers, university representatives, industry representatives and research organisations to discuss and analyse ways forward for the promotion of U-I collaborations in the country. A key feature of the workshop was participant interaction, where the participants worked in five focus groups to identify current barriers and potential opportunities for U-I collaborations in Pakistan. 
One dominant message from this workshop is that there is a lack of leadership vision from all major stakeholders (i.e. Government, Academia, Industry and Community at large) to make U-I collaborations work effectively in Pakistan. Part of this problem is the lack of trust and understanding between universities and industry which acts as a major impediment. Hence, there is great potential and need for the inclusion of industry people to enter academia and for academics to work in industry, which could be initiated via some policy measures to promote the mobility of staff from both sides (universities and industry) to spend some time immersed in each other's operating environments, as mentioned by many of the workshop participants. Similar to insights obtained from our survey and interviews, this workshop stressed the fact that academics might be better incentivised to collaborate with industry if this was given similar parity to producing research publications and holding patents when applying for promotions.

There was a strong desire to see U-I collaboration policies formulated with a clear path towards leading to societal benefits for the nation, seen to impact long-term employment growth in more knowledge intensive areas and capacity building (e.g. skills upgrading) of the local workforce. A related concern is that most SMEs have no R\&D capability to take full advantage of U-I collaborations that might ultimately help improve innovation efforts. One idea strongly floated was for Government to incentivise R\&D projects in SMEs via some form of policy measure that can cover full or partial cost of R\&D projects where the firm is going to collaborate with a university partner.

\section{Analysing current challenges and future opportunities}

Our empirical results indicate that most Pakistani industrial firms are reluctant or unable to make adequate investments for $\mathrm{R} \& \mathrm{D}$, and many universities lack the finances to fully exploit different forms of collaboration with industry. Hence, the government could consider promoting U-I collaboration via new policy measures that can alleviate financial difficulties 
faced by universities and especially SME industrial firms. For example, the government support could be provided in the form of grants that enable the university and industry partner to share some financial risks associated with the setting-up of new research collaboration projects. Such policy measures should help to stimulate innovation and may provide wider economic benefits for the economy. From the university side, one type of funding mechanism that can assist university academic staff to make more effective connections with industry is where this can lead to the commercialisation of new technologies leading to new industrial applications. Hence enabling technology transfer from the university to an industrial firm. Here it also worthwhile mentioning that in order to make these connections work well, university research staff need to firstly gain the necessary support from their university to help develop and upgrade some skills. Govindaraju et al.'s (2009) study of Malaysian universities, confirmed that this type of support enabled research staff to ascertain a better knowledge about commercial market demands and intellectual property ownership, when collaborating on industry projects that might lead to the development of new technological products.

The difference of intentions amongst universities and industrial firms appears to be a major barrier for the widespread promotion of U-I collaborations in Pakistan. Our findings confirm that this divergence of objectives manifests itself in a number of ways including: some firms do not see universities as a trustworthy collaborator; universities have limited knowledge about the specific requirements of industry partners; SMEs are unaware of key developments taking place in universities; and there is insufficient experience in new product development.

A major challenge for university-industry engagement in developing countries, as confirmed by a Sri Lankan U-I collaboration study (Wickramasinghe \& Malik, 2018), is the difficulty of 'contextual understanding' between people from different organisations. 
Therefore, distinct actors and personalised competencies are likely to be of prominence in industry-academia partnerships, because relational social capital and belief is not a common spread phenomenon amongst industrial firms and universities in numerous developing countries (Schiller \& Lee, 2015). Hence, key individuals or small organisational units with the knowledge and enthusiasm for making U-I collaborations work might be pivotal in helping to afford the required organisational resources and expertise to help show some mutual advantages offered by U-I collaborations to others. We posit that ORIC offices might be best placed to take up this type of role in Pakistani universities.

As confirmed through our empirical analysis, there does appear to be a lack of strong interest in U-I collaborations from the industry side in Pakistan, not helped by some negative experiences of collaboration in the recent past. This can be linked to a need to not only introduce policy measures that incentivise industrial firms to take advantage of R\&D undertaken in universities, but this should also be balanced with efforts to strengthen the key actors involved (large firms, SMEs, universities and public research organisations). In this context, Amanatidou et al. (2016) indicate that future government policy should ensure that firms can be supported to access knowledge residing in an economy's scientific and research institutions with ease. Hence bringing the science base closer to society. The frequency of institutional disintegration in developing countries can often hinder U-I collaborations, such as the process of moving technological breakthroughs from research institutions into the development of innovations inside industrial (Saad et al., 2008; Bhutto \& Lohana, 2018). Historically, the lack of science and technology development in Pakistan can be attributed to a lack of connection amongst important actors, including the government, key research units, universities, and the users of agencies such as business and the agriculture and service sectors (Naim, 2001). 
From our empirical data, student industry work placements and some form of industry input into university teaching course content were highlighted as promising ways to promote future U-I collaboration in Pakistan. According to Laredo (2007) and Borah et al. (2019), the analysis of U-I collaborations in the literature has neglected to consider the impact of U-I collaborations on university teaching outputs. One of the key issues raised in our workshop and interviews, which specifically addressed educational matters, was that students at university can play an important role in enabling the transfer of knowledge from universities into industry, as well as some reverse knowledge transfer back into universities. Woolgar (2007) states that some level of co-development of a university curriculum with industrial partners can offer universities the flexibility to make use of industry executives as teachers on temporary assignments. Some larger Pakistani technology-based companies could consider instigating collaborations with engineering based universities. For example, the Indian IT company Infosys has run a 'campus connect' initiative from 2004, whereby the company has managed to initiate collaborations with over 400 engineering institutes across India to deliver IT courses. This initiative started because of rising concern amid the Indian IT industry that students graduating with degrees from the country's engineering universities lacked suitable skills to easily move into industry (De Meyer \& Williamson, 2016).

\section{Conclusion}

Any overall conclusions drawn from this exploratory study can only be tentative, since the findings presented represent a snapshot of the current challenges and opportunities for promoting U-I collaborations in Pakistan. We have attempted to present the diversity of input from key stakeholders by obtaining some insightful data via a survey, interviews and from workshop focus groups. 
Although there is currently limited evidence of university-industry interaction in Pakistan, one major recommendation of the Islamabad workshop was to encourage national government and any international bodies to help facilitate more forums where industry, academia and any other interested actors can come together and devise practical ideas for the growth of U-I collaborations in Pakistan. This links to a more profound issue of developing the scientific and research culture across Pakistan. One practical way to develop this culture is to look at ways of bringing together key actors from universities and industry via forums such as seminars and conferences that address issues of strategic importance for all actors.

In policy terms, one key issue arising for policymakers is to look at ways to simplify the regulatory framework, which can help to facilitate efforts in the co-development of some university curriculums with industry partners. This should also help expose academic faculty to new insights from industry practitioners that may lead to more formal engagement with industry in the future. More widely for developing countries, for the training and research undertaken inside universities to contribute to the economic development process, there needs to be effective linkages between universities and the firms and sectors involved in the production of goods and services.

Finally, our empirical findings are limited by our methodology. Although following a qualitative approach enabled us to obtain some rich exploratory research insights into the challenges and opportunities of promoting U-I collaborations in Pakistan, we cannot generalise beyond our limited sample. Thus, future research could connect with a higher number of industrial firms, possibly through workshops, interviews with key managers who may be attempting to initiate collaborations with universities, and questionnaire surveys to industrial firms. Workshop type events could be facilitated in collaboration with regional actors such as chambers of commerce, technology park management offices, universities 
located near science parks or industry associations, as this may help to raise more awareness about U-I collaborations to SME firms.

\section{References}

Afzal, S., Ahmad, K., Qureshi, M., Zaman, K. \& Khan, N. (2014). Empirical analysis of university-industry R\&D collaboration: Evidence from Pakistan. Management Science Letters, 4(8), 1725-1740.

Ali, M., \& Tahir, M. (2017). Success of Industry-Academia Collaboration Model in Bahria University Karachi. Bahria University Research Journal of Earth Sciences, 2, 61-63.

Amanatidou, E., Saritas, O. \& Loveridge, D. (2016). Strategies for emerging research and innovation futures. Foresight, 18(3), 253-275.

Bashir, T., Khan, K., \& Malik, K. (2010). The innovation lanscape of Pakistan's North West Frontier Province. Science and Public Policy, 37(3), 181-191.

Bhutto, A., \& Lohana, K. (2018). Analysing existence of university-industry-government linkages in Sindh, Pakistan. Science, Technology and Development, 37(1), 42-55.

Borah, D., Malik, K., \& Massini, S. (2019). Are engineering graduates ready for R\&D jobs in emerging countries? Teaching-focussed industry-academia collaboration strategies. Research Policy, 48(9), 103837.

Cavallone, M., Ciasullo, M., Douglas, J., Palumbo, R. (2019). Framing higher education quality from a business perspective: setting the conditions for value co-creation. Studies in Higher Education, 1-13. DOI: 10.1080/03075079.2019.1672644

De Meyer, A., \& Williamson, P. (2016). Closing the talent gap in India's IT sector. Asian Management Insights, 1(2), 42-49. 


\section{Galvao, A., Mascarenhas, C. \& Marques, C. (2020). Knowledge spillovers between universities and companies of low-density territories. Knowledge Management Research \& Practice, DOI: 10.1080/14778238.2020.1829516.}

Garcia, R., Araújo, V., Mascarini, S., Santos, E. \& Costa, R. (2020). How long-term university-industry collaboration shapes the academic productivity of research groups. Innovation: Organization \& Management, 22(1), 56-70.

Government of Pakistan (2012). National Science, Technology and Innovation Policy 2012. Ministry of Science and Technology, available at: http://most.comsatshosting.com/Policies/National $\% 20$ Science, $\% 20$ Technology $\% 20$ and $\% 2$ 0Innovation\%20Policy\%202012.pdf (accessed 7 February 2021)

Govindaraju, V., Ghapar, F., \& Pandiyan, V. (2009). The role of collaboration, market and intellectual property rights awareness in university technology commercialization. International Journal of Innovation and Technology Management, 6(4), 363-378.

Higher Education Commission (2017). Business Incubation Centres in Public Sector Universities, available at: http://hec.gov.pk/english/services/universities/EBIC/Pages/default.aspx (accessed 7 February 2021)

Howells, J. (2006). Intermediation and the role of intermediaries in innovation. Research Policy, 35(5), 715-728.

Knudsen, M., Frederiksen, M. \& Goduscheit, R. (2019). New forms of engagement in third mission activities: a multi-level universitycentric approach. Innovation: Organization \& Management, DOI: 10.1080/14479338.2019.1670666.

Laredo, P. (2007). Revisiting the third mission of universities: toward a renewed categorization of university activities? Higher Education Policy, 20(4), 441-456. 
Mascarenhas, C., Ferreira, J. \& Marques, C. (2018). University-industry cooperation: A systematic literature review and research agenda. Science and Public Policy, 45(5) 708718.

Naim, T. (2001). Science and Technology Development in Pakistan. Science, Technology \& Society, 6(1), 97-132.

Patana, A., Pihlajamaa, M., Polvinen, K., Carleton, T. \& Kanto, L. (2013). Inducement and blocking mecahnisms in the Finnish life sciences innovation system. Foresight, 15(6), 428-455.

Piirainen, K., Andersen, A. \& Andersen, P. (2016). Foresight and the third mission of universities: the case for innovation system foresight. Foresight, 18(1), 24-40.

Pittayasophon, S. \& Intarakumnerd, P. (2017). University and industry collaboration in Japan and Thailand: influence of university type. Asian Journal of Technology Innovation, 25(1), 23-40.

Planning Commission (2014). Pakistan 2025. Ministry of Planning, Development \& Reform, Government of Pakistan, available at:

http://pc.gov.pk/uploads/vision2025/Vision-2025-Executive-Summary.pdf (accessed 7 February 2021)

Saad, M., Zawdie, G., \& Malairaje, C. (2008). The triple helix strategy for universities in developing countries: the experiences in Malaysia and Algeria. Science and Public Policy, $35(6), 431-443$.

Scandura, A. (2016). University-industry collaboration and firms' R\&D effort. Research Policy, 45(9), 1907-1922.

Schiller, D., \& Lee, K. (2015). Are university-industry links meaningful for catch up? A comparative analysis of five Asian countries. In: E. Albuquerque, W. Suzigan, G. Kruss \& K. Lee (Eds.), Developing National Systems of Innovation (pp. 55-92), Cheltenham: Edward Elgar. 
Shohert, S., \& Prevezer, M. (1996). UK biotechnology: institutional linkages, technology transfer and the role of intermediaries. R\&D Management, 26(3), 283-298.

Sin, C. \& Amaral, A., (2017). Academics' and employers' perceptions about responsibilities for employability and their initiatives towards its development. Higher Education, 73(1), 97-111.

Smirnova, Y. (2016). University-industry knowledge transfer in an emerging economy: Evidence from Kazakhstan. Science and Public Policy, 43(5), 702-712.

Strauss, A., \& Corbin, J. (1998). Basics of Qualitative Research Techniques. Sage publications, Thousand Oaks, CA.

UNESCO (2015). UNESCO Science Report: towards 2030. Paris: United Nations Educational, Scientific and Cultural Organization.

Universities UK International (2017). Pakistan Higher Education Vision 2025, available at: https://www.universitiesuk.ac.uk/policy-andanalysis/reports/Documents/International/PakistanHE_iNotes_June17 final.pdf (accessed 7 February 2021)

Vásquez-Urriago, A., Barge-Gil, A., \& Modrego Rico, A. (2016). Science and Technology Parks and cooperation for innovation: Empirical evidence from Spain. Research Policy, 45(1), 137-147.

Wickramasinghe, V., \& Malik, K. (2018). University-Industry Collaboration in Sri LankaA Developing Country Perspective. International Journal of Innovation and Technology Management, 15(4), 1850032.

Woolgar, L. (2007). New institutional policies for university-industry links in Japan. Research Policy, 36(8) 1261-1274. 
Zaman, K. (2011). Review of Pakistan pharmaceutical industry: SWOT analysis. Int. Jnl. of Business \& Information Technology, 1(2), 114-117. 
Table I Mechanisms for establishing U-I collaboration.

\begin{tabular}{|c|c|c|c|c|c|}
\hline Mechanisms & $\begin{array}{l}1=\text { Not } \\
\text { important }\end{array}$ & $\begin{array}{l}2=\text { Slightly } \\
\text { important }\end{array}$ & $\begin{array}{l}3=\text { Moderately } \\
\text { important }\end{array}$ & $4=$ Important & $\begin{array}{c}5=\text { Most } \\
\text { important }\end{array}$ \\
\hline $\begin{array}{l}\text { Invention originating in university } \\
\text { leading to new knowledge /or } \\
\text { formation of new technology } \\
\text { companies, with academic inventors } \\
\text { moving out (in part or whole) of } \\
\text { university to become entrepreneurs. }\end{array}$ & 0 & 0 & 4 & 13 & 16 \\
\hline $\begin{array}{l}\text { Participation in research contract and } \\
\text { joint research }\end{array}$ & 0 & 0 & 3 & 14 & 16 \\
\hline $\begin{array}{l}\text { Invention originating in } \\
\text { university/institution taken up by } \\
\text { existing industrial companies }\end{array}$ & 0 & 0 & 5 & 14 & 14 \\
\hline $\begin{array}{l}\text { Consultancy to industry by academic } \\
\text { staff }\end{array}$ & 0 & 0 & 1 & 22 & 10 \\
\hline Analysis and testing in industry & 1 & 0 & 5 & 17 & 10 \\
\hline $\begin{array}{l}\text { Personal contact via conference/ } \\
\text { seminar type networking with } \\
\text { industrial staff }\end{array}$ & 0 & 1 & 10 & 13 & 9 \\
\hline $\begin{array}{l}\text { Access to specialised technical } \\
\text { reports, equipment and industrial } \\
\text { R\&D }\end{array}$ & 0 & 2 & 7 & 15 & 9 \\
\hline $\begin{array}{l}\text { Part-time secondment of academic } \\
\text { staff to industry }\end{array}$ & 1 & 0 & 12 & 11 & 8 \\
\hline $\begin{array}{l}\text { Academic staff as non-executive } \\
\text { directors in industry }\end{array}$ & 3 & 5 & 9 & 15 & 2 \\
\hline
\end{tabular}

Source: authors' original work. 
Table II Barriers preventing U-I collaboration with industry.

\begin{tabular}{|c|c|c|c|c|}
\hline Barriers & $1=$ Not significant & $\begin{array}{c}2=\text { Moderately } \\
\text { significant }\end{array}$ & $\begin{array}{c}3=\text { Very } \\
\text { significant }\end{array}$ & Mean \\
\hline $\begin{array}{l}\text { Industry does not consider the university to } \\
\text { be reliable partners }\end{array}$ & 5 & 8 & 21 & 2.83 \\
\hline $\begin{array}{l}\text { No/few rewards for academics to work with } \\
\text { industry }\end{array}$ & 2 & 14 & 18 & 2.83 \\
\hline Poor knowledge of industry-relevant needs & 6 & 9 & 18 & 2.75 \\
\hline $\begin{array}{l}\text { Insufficient experience in new product } \\
\text { development and commercialisation }\end{array}$ & 3 & 14 & 16 & 2.75 \\
\hline $\begin{array}{l}\text { We cannot respond to the needs of industry } \\
\text { because our equipment base and facilities } \\
\text { are insufficient }\end{array}$ & 7 & 10 & 16 & 2.75 \\
\hline $\begin{array}{l}\text { Working with industry is not an expected } \\
\text { role for us }\end{array}$ & 12 & 10 & 11 & 2.75 \\
\hline $\begin{array}{l}\text { Working with industry leads to delay of } \\
\text { publications }\end{array}$ & 18 & 10 & 5 & 2.75 \\
\hline $\begin{array}{l}\text { Working with industry does not influence } \\
\text { academic promotions }\end{array}$ & 8 & 5 & 19 & 2.67 \\
\hline $\begin{array}{l}\text { Collaboration with industry is problematic } \\
\text { due to difference in objectives of University } \\
\text { and Firm }\end{array}$ & & 12 & 18 & 2.67 \\
\hline $\begin{array}{l}\text { Working with industry does not influence } \\
\text { institutional funding by the Government }\end{array}$ & 10 & 9 & 13 & 2.67 \\
\hline $\begin{array}{l}\text { Restrictions on intellectual property rights } \\
\text { arising from research collaboration with } \\
\text { industry }\end{array}$ & 6 & 19 & 7 & 2.67 \\
\hline $\begin{array}{l}\text { The work needed by industry is not always } \\
\text { interesting (important) for us }\end{array}$ & 17 & 9 & 6 & 2.67 \\
\hline Other (please mention) & 0 & 0 & 1 & 0.08 \\
\hline
\end{tabular}

Source: authors' original work. 
Table III University staff and student engagement with industry.

\begin{tabular}{lcc}
\hline Engagement with industry & Yes & No \\
\hline $\begin{array}{l}\text { Does your university have a formal policy allowing } \\
\text { faculty members of staff to pursue outside activities such as } \\
\text { consultancy to industry? }\end{array}$ & 18 & 16 \\
& $(53 \%)$ & $(47 \%)$ \\
$\begin{array}{l}\text { Do you think faculty members should be evaluated according to } \\
\text { the extent of their contributions to industry collaboration, similar to } \\
\text { evaluating their research and teaching? }\end{array}$ & $\begin{array}{l}29 \\
\end{array}$ & $55 \%)$ \\
$\begin{array}{l}\text { Does your university encourage students to conduct any research } \\
\text { projects inside firms or in collaboration with industry? }\end{array}$ & 31 & $(15 \%)$ \\
& $(91 \%)$ & $(9 \%)$ \\
$\begin{array}{l}\text { Do you have any (formal or informal) feedback from industry } \\
\text { about any educational or training courses offered by your } \\
\text { university? }\end{array}$ & 19 & 15 \\
\end{tabular}

Source: authors' original work. 
Figure 1 Most frequent mode of industry collaboration pursued by universities

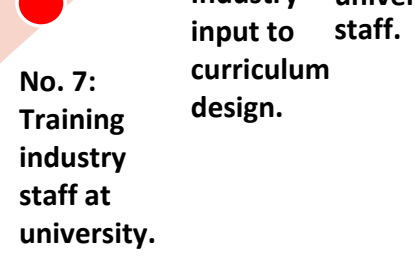
input to staff. design.

No. 3:

No. 4:

Consultancy

to industry

Joint

conference or

seminar

No. 5: Research

by academic event.

staff.

No. 6: contracted

Industry university

Source: authors' original work. 


\title{
Figure 2 Highest ranked barriers that prevent universities collaborating with industry
}

\author{
No. 1 Industry does not consider the university to be reliable partners. \\ No.2 \\ - No/few rewards for academics to work with industry. \\ - Poor knowledge of industry-relevant needs. \\ No.4 - Insufficient experience in new product development and commercialisation.
}

- We cannot respond to the needs of industry because our equipment base and facilities are No.5 insufficient.

No.6

- Working with industry is not an expected role for us.

- Working with industry leads to delay of publications.

Source: authors' original work. 